\title{
O universal e o particular na linguística geral de Benveniste
}

\author{
Valdir do Nascimento Flores ${ }^{1}$ \\ Programa de Pós-graduação em Letras da Universidade Federal do Rio Grande do Sul, Porto Alegre, RS, Brasil
}

Resumo: Este texto busca apresentar uma interpretação da teoria da linguagem de Émile Benveniste segundo a qual as categorias de pessoa, tempo e espaço - constitutivas da enunciação - seriam evidências da relação entre aspectos universais da linguagem e aspectos particulares, das línguas. Tais categorias permitem falar em universais de natureza antropológica numa teoria da linguagem. O percurso teórico-conceitual é feito a partir da interpretação de textos do linguista, em especial aqueles em que são elaboradas as reflexões que integram a quinta parte dos dois volumes de Problemas de linguística geral. A conclusão sinaliza que é uma perspectiva dos estudos linguísticos desenvolver a dimensão antropológica dessas categorias em diferentes línguas.

Palavras-chave: Linguística Geral; Universais Linguísticos; Émile Benveniste.

Title: The universal and the particular in Benveniste's general linguistics

Abstract: This text presents an interpretation of Émile Benveniste's theory of language, according to which the categories of person, time and space - constitutive of enunciation - are evidences of the relation between universal aspects of language and particular aspects of different languages. Such categories enable us to speak of universals of an anthropological nature within a theory of language. The theoretical-conceptual approach is based on an interpretation of the linguist's texts, especially those in which he expresses the thoughts that are included in the fifth part of the two volumes of Problems in General Linguistics. The conclusion indicates that developing the anthropological dimension of these categories in different languages is one of the perspectives of linguistic studies.

Keywords: General Linguistics; Linguistic Universals; Émile Benveniste.

\section{Primeiras palavras}

O grande linguista Antoine Culioli, em um lindo texto ("Théorie du langage et théorie des langues"), apresentado em um colóquio em homenagem a Émile Benveniste e ocorrido em Tours, França, em 1983², é um dos primeiros a formular uma interpretação da obra de Benveniste que põe em relação a diversidade das línguas e a linguagem: "eu direi que Benveniste me parece ser o linguista que colocou, de forma explícita e particularmente

\footnotetext{
${ }^{1}$ Doutor em Linguística pela Pontifícia Universidade Católica do Rio Grande do Sul (PUCRS). Pós-doutorado Université de Paris XII-Val-de-Marne e Université de Paris X-Nanterre. Professor Titular de Linguística e Língua Portuguesa do curso de graduação em Letras da Universidade Federal do Rio Grande do Sul (UFRGS). É pesquisador PQ-CNPQ. Orcid: https://orcid.org/0000-0003-2676-3834. E-mail: vnf.ufrgs@gmail.com

${ }^{2}$ A versão do texto aqui utilizada é a presente em Culioli (1999).
} 
teorizada que o objeto da linguística era o estudo da relação entre a linguagem e as línguas" (CULIOLI, 1999, p. 117, destaque do autor). Culioli lembra que, já no "Prefácio" de Problemas de linguística geral I, Benveniste antecipa essa relação como sendo uma das balizadoras de sua linguística:

[...] a linguagem é, de fato, um objeto difícil e [...] a análise do dado linguístico se faz por árduos caminhos. [...] será necessário compenetrar-se desta verdade: a reflexão sobre a linguagem só produz frutos quando se apoia, primeiro, sobre as línguas reais. $O$ estudo desses organismos empíricos, históricos, que são as línguas permanece o único acesso possível à compreensão dos mecanismos gerais e do funcionamento da linguagem (BENVENISTE, 1988, s. p.).

Em 1963, em um artigo dedicado a traçar uma espécie de história recente das transformações ocorridas na ciência linguística, Benveniste explicita mais claramente sua opinião acerca das relações entre as línguas e a linguagem:

\begin{abstract}
Comecemos por observar que a linguística tem duplo objeto: é ciência da linguagem e ciência das línguas. Essa distinção, que nem sempre se faz, é necessária: a linguagem, faculdade humana, característica universal e imutável do homem, não é a mesma coisa que as línguas, sempre particulares e variáveis, nas quais se realiza. É das línguas que se ocupa o linguista e a linguística é em primeiro lugar a teoria das línguas. Dentro da perspectiva em que nos aqui colocamos, veremos que essas vias diferentes se entrelaçam com frequência e finalmente se confundem, pois os problemas infinitamente diversos das línguas têm em comum o fato de que, a um certo grau de generalidade, põem sempre em questão a linguagem (BENVENISTE, 1988, p. 20).
\end{abstract}

Observe-se que a comparação da primeira passagem de Benveniste antes citada com a segunda faz ressaltar um importante acréscimo. Inicialmente, no "Prefácio", as línguas são o único acesso possível à linguagem, quer dizer, o estudo das línguas, dos organismos empíricos, permite que se chegue à compreensão dos mecanismos gerais da linguagem. Disso decorre que uma possibilidade de estudar as línguas é procurar o que há nelas que pode revelar o funcionamento geral da linguagem. Cabe destacar que a ênfase de Benveniste, aqui, é, sobretudo, com relação ao estudo da linguagem; as línguas se configuram, nesse caso, como via de acesso à linguagem. É nesse sentido que se pode entender a afirmação - ponto de partida da formulação ali posta - de que "a reflexão sobre a linguagem só produz frutos quando se apoia, primeiro, sobre as línguas reais" ou, ainda, a a conclusão de que "a linguagem é, de fato, um objeto difícil".

Coisa relativamente diferente se dá na segunda passagem. Nesse caso, em primeiro lugar, linguagem e línguas recebem, ambas, status de objeto da linguística; em segundo lugar, a linguagem é claramente qualificada como universal e as línguas, como particulares; em terceiro lugar, é determinado que, ao linguista, cabe o estudo das línguas; em quarto lugar, a diferença que há entre as línguas coloca em questão a linguagem. Em suma, pode-se dizer que, nessa passagem, Benveniste raciocina em direção quase inversa à que formula no "Prefácio". Aqui, lê-se que é das línguas que se ocupa o linguista; o estudo da linguagem não passa de uma decorrência desse estudo das línguas. 
Além dessas diferenças de direção de raciocínio entre as duas citações acima, há um ponto que está apenas implícito na primeira e absolutamente explícito na segunda: a distinção universal/particular. Parece evidente que Benveniste assume a perspectiva de que a linguagem tem um aspecto universal, ao passo que as línguas têm aspectos particulares $e$ variáveis. Ora, embora, aparentemente, essa formulação não apresente maiores problemas de compreensão, ela não deixa entrever o que exatamente Benveniste entende pelos termos universal e particular, no escopo de sua linguística. E compreender isso é de especial importância, uma vez que há, nas muitas linguísticas pós-saussurianas, distintas maneiras de conceber o que cabe a cada um dos elementos do par universal/particular ${ }^{3}$.

É esse o ponto de interesse do presente trabalho: os termos pelos quais Benveniste apresenta as diferenças e as relações entre o que é de ordem universal e o que é de ordem particular no estudo da linguagem e das línguas em sua linguística geral. Busca-se, em última análise, investigar os limites e o alcance de tal formulação.

\section{O particular das línguas}

Observem-se as passagens abaixo, todas retiradas de Problemas de linguística geral I:

a) "Não se cede mais tão facilmente como antes à tentação de erigir como propriedades universais da linguagem as particularidades de uma língua ou de um tipo linguístico" (BENVENISTE, 1988, p. 6).

b) "[...] as categorias linguísticas são sempre categorias de uma língua particular" (BENVENISTE, 1988, p. 70).

c) "[...] ilusão que nos faz tomar as categorias da nossa própria língua como necessárias e universais" (BENVENISTE, 1988, p. 87).

d) "As distinções que cada língua manifesta devem ser relacionadas com a lógica particular que as sustenta e não submetidas de imediato a uma avaliação universal" (BENVENISTE, 1988, p. 89).

Em todas as passagens, é relativamente fácil ver que Benveniste utiliza a distinção universal/particular para, de um lado, preservar o que é específico de cada língua e, de outro lado, evitar que se identifique - de maneira direta e conclusiva - o particular de uma língua às propriedades universais da linguagem.

Em (a), vê-se que as particularidades de uma língua não podem ser alçadas a propriedades universais. Por exemplo, na análise que faz da língua ewe, falada no Togo, Benveniste mostra que a noção presente no verbo "ser" do grego se distribui em cinco verbos em ewe ${ }^{4}$. Além disso, Benveniste mostra que esses cinco verbos em ewe - que corresponderiam ao verbo "ser" do grego - apenas podem ser considerados desse ponto de vista a partir do grego - portanto, de maneira externa ao ewe -, pois, "no interior da morfologia ou da sintaxe ewe, nada aproxima esses cinco verbos entre eles. É com relação

\footnotetext{
${ }^{3}$ Como, por exemplo, a distinção, operada por Chomsky, entre universais formais e universais substanciais, conforme tratado em Flores (2019), em especial no item 10.3.1, intitulado “Universal ou universais?”.

"Essa análise é tratada em detalhe em Flores (2019), no capítulo "A língua e o pensamento".
} 
aos nossos próprios usos linguísticos que Ihes descobrimos qualquer coisa em comum" (BENVENISTE, 1988, p. 79, destaque do autor). Logo, trata-se de uma análise que esclarece, principalmente, o grego, na medida em que aborda um fato que é próprio das línguas indoeuropeias e não uma situação universal. Em (b), (c) e (d), vê-se um argumento que vai na mesma direção.

O raciocínio de Benveniste fica bem claro quando, em texto de 1950, "A frase nominal", o linguista analisa a diferença entre verbo e nome. Segundo ele, as definições geralmente se limitam ou a considerar que o verbo indica processo e o nome indica objeto ou a considerar que o verbo implica tempo e o nome não. Para Benveniste, essas definições são inaceitáveis para um linguista, porque

uma oposição entre "processo" e "objeto" não pode ter em linguística nem validade universal, nem critério constante, nem mesmo sentido claro. A razão está em que noções como processo ou objeto não reproduzem os caracteres objetivos da realidade mas resultam de uma expressão já linguística da realidade, e essa expressão só pode ser particular. Não são propriedades intrínsecas da natureza que a linguagem registraria, são categorias formadas em certas línguas e que foram projetadas sobre a natureza. A distinção entre processo e objeto só se impõe àquele que raciocina a partir das classificações da sua língua nativa, que ele transforma em dados universais; e inclusive esse, interrogado sobre o fundamento dessa distinção, virá logo a reconhecer que, se "cavalo" é um objeto e "correr" um processo, é porque um é nome, o outro, um verbo. Uma definição que procure uma justificativa "natural" para a maneira pela qual um idioma particular organiza suas noções, é condenada a girar em círculo (BENVENISTE, 1988, p. 164-165, destaques do autor).

Bem entendido o que disse Benveniste, é-se levado a concluir que a distinção entre processo e objeto está circunscrita a determinados idiomas e não pode ser generalizada, logo não tem valor universal e não passa de particularidade de uma língua. É exatamente isso que se depreende da continuidade da análise do linguista:

[...] é suficiente aplicá-la [a definição que supõe a distinção entre processo e objeto] a idiomas de um tipo diferente para ver que a relação entre objeto e processo pode inverter-se e mesmo abolir-se, permanecendo as mesmas as relações gramaticais. Em hupa (Oregon), empregam-se como nomes formas verbais ativas ou passivas na terceira pessoa: nañya, "ele desce", e a palavra para "chuva"; nilliñ, "ele escorre", designa o "riacho"; naxōwilloi i, "está atado ao redor dele", denomina a "cinto", etc. Em zuñi, o nome yätokä, "sol", e uma forma verbal de yäto-, "atravessar". Inversamente, podem constituir-se formas verbais sobre noções que não correspondem àquilo a que chamaríamos processos. Em siuslaw (Oregon), partículas como wahá, "de novo", y $\bar{a}^{\alpha} x a$, "muito", conjugam-se verbalmente. A conjugação dos adjetivos, dos pronomes interrogativos e sobretudo dos numerais caracteriza um grande número de línguas ameríndias (BENVENISTE, 1988, p. 165, destaques do autor).

Essas passagens, retiradas das complexas análises de Benveniste, são suficientes para concluir, ao menos parcialmente, que a análise das línguas tem, para o linguista, a importância de dar a ver o que é próprio de cada língua: sua configuração gramatical, suas categorias, suas noções, enfim, seu modo de ser. 
A maneira como Benveniste concebe sua linguística dá às línguas um lugar complexo, não redutível a algum rótulo pré-estabelecido (relativismo, determinismo, universalismo etc.). Sua abordagem das línguas permite-lhe colocá-las em um lugar epistemológico, no interior de sua teoria da linguagem, que evoca grandes questões transversais à linguística.

Em primeiro lugar, as relações entre o pensamento e as línguas: "pensamos um universo que a nossa língua, em primeiro lugar, modelou" (BENVENISTE, 1988, p. 7). Sem dúvida, também, a cultura e as línguas: "a diversidade das línguas, a diversidades das culturas, as suas mudanças mostram a natureza convencional do simbolismo que as articula" (BENVENISTE, 1988, p. 32). Ainda, a sociedade e as línguas: “[...] a linguagem se realiza sempre dentro de uma língua, de uma estrutura linguística definida e particular, inseparável de uma sociedade definida e particular. Língua e sociedade não se concebem uma sem a outra" (BENVENISTE, 1988, p. 31, destaque do autor). Também, o real (no sentido de realidade) e as línguas: "as línguas não nos oferecem de fato senão construções diversas do real" (BENVENISTE, 1989, p. 70); por exemplo: "não há duas línguas que organizem as cores da mesma maneira. Seriam os olhos diferentes? Não. É a língua que é diferente" (BENVENISTE, 1989, p. 21). Finalmente, o homem e as línguas: "[...] o homem não dispõe de nenhum outro meio de viver o 'agora' [...]. Poder-se-ia mostrar pelas análises de sistemas temporais em diversas línguas a posição central do presente" (BENVENISTE, 1989, p. 85, destaque do autor).

Tais considerações acerca das línguas, como lugar do "particular" na teoria da linguagem de Benveniste, podem levar a concluir que, para o linguista, as línguas são o reino do individual, nada havendo de generalizável, de unificador, no conjunto heterogêneo das diversas línguas. Não é nada disso.

Benveniste se esforça, também, para articular as línguas a um aspecto universal. Leia-se: "Todas as línguas têm em comum certas categorias de expressão que parecem corresponder a um modelo constante" (BENVENISTE, 1989, p. 68). De que natureza é esse "modelo constante"? Qual sua configuração? É sobre ele que se trata a seguir.

\section{O universal da linguagem: o antropológico}

É bom não se enganar com a palavra linguagem no subtítulo que encabeça esta seção: não há apenas uma noção de linguagem na obra de Benveniste. O autor, inclusive, é conhecido pela flutuação terminológica que caracteriza a sua obra. Há, no conjunto de seus escritos, termos, noções e relações conceituais que, presentes em alguns artigos, não se repetem em outros estudos nem em diferentes épocas da obra ${ }^{5}$.

Uma das noções de linguagem mais importantes formulada por Benveniste é a que coloca em relação o homem e a função simbólica - "[...] a linguagem representa a mais alta forma de uma faculdade que é inerente à condição humana, a faculdade de simbolizar" (BENVENISTE, 1988, p. 27, destaque do autor) -, uma faculdade exclusiva do homem, que

\footnotetext{
${ }^{5}$ Para tratar a flutuação terminológica e conceitual da obra de Benveniste, ver Flores (2013a), em especial, o capítulo "Itinerário de leitura da teoria enunciativa de Émile Benveniste".
} 
"[...] está na base das funções conceptuais" (BENVENISTE, 1988, p. 29) e que é o sistema simbólico por excelência, que "[...] torna a experiência interior de um sujeito acessível a outro numa expressão articulada e representativa" (BENVENISTE, 1988, p. 30). No entanto, não é desse aspecto da linguagem que se tratará aqui, embora não se the oponha nada. Interessa, neste momento, ver o que há, aos olhos de Benveniste, de geral na linguagem que permite unir a diversidade das línguas, ou ainda, nas palavras de Benveniste, "falamos realmente da linguagem e não apenas das línguas particulares. Os fatos das línguas particulares, que concordam, testemunham pela linguagem" (BENVENISTE, 1988, p. 287).

Ora, não por acaso, essa última passagem citada se encontra em um texto de 1958 em que Benveniste aborda a grande questão da subjetividade na linguagem. Nesse texto, o autor, entre outras coisas, busca estabelecer o fundamento linguístico da subjetividade que, segundo ele, deve-se à linguagem. Quer dizer, a subjetividade é inerente - no sentido de ser constitutiva - à linguagem, e as línguas não fazem mais do que "testemunhar" isso através de categorias linguísticas.

Em artigo posterior, de 1965, cujo título já anuncia os termos do que será estudado "A linguagem e a experiência humana" -, ele destaca duas categorias (pessoa e tempo) que permitem ver a experiência subjetiva de cada um em sua língua:

São categorias elementares, independentes de toda determinação cultural e nas quais vemos a experiência subjetiva dos sujeitos que se colocam e se situam na e pela linguagem. Tentaremos aqui esclarecer duas categorias fundamentais do discurso, aliás necessariamente ligadas, a de pessoa e a de tempo (BENVENISTE, 1989, p. 68).

Anos antes, em artigo de 1956, Benveniste já destacava as três instâncias - pessoa, tempo e espaço - em relação com o que viria a ser conhecido com o nome de enunciação, anos mais tarde: "o essencial é, portanto, a relação entre o indicador (de pessoa, de tempo, de lugar, de objeto mostrado, etc.) e a presente instância de discurso" (BENVENISTE, 1988, p 280, destaques do autor).

Conforme explicado em Flores (2019, p. 76-77), as categorias de pessoa, tempo e espaço formam conjuntamente um dispositivo constitutivo de todas as línguas, que permite a inscrição do homem em sua fala. É uma espécie de sistema universal que permite que cada falante singularize a língua, torne-a sua.

Essas categorias elementares são universais que unificam as línguas. Mas universais de que natureza? Certamente, Benveniste não está falando, aqui, de alguma propriedade biológica, fisiológica ou mesmo psicológica. Em uma palavra, pode-se dizer que o universal visado por Benveniste é de natureza antropológica. Isso precisa ser mais bem desenvolvido.

Observe-se, especialmente na citação acima de "A linguagem e a experiência humana", que Benveniste apresenta as categorias de pessoa e tempo como ligadas entre si e relativas a uma experiência dos sujeitos, do homem, portanto.

A pessoa é uma categoria que permite a "atualização de uma experiência essencial, da qual não se concebe que o instrumento possa jamais faltar a uma língua" (BENVENISTE, 2005 , p. 68). Tal categoria de linguagem não pode ser reduzida a uma categoria de língua; 
ela apenas comparece nas línguas, e isso através, agora sim, de determinadas categorias linguísticas: "não consideramos as formas específicas dessa categoria nas línguas dadas, e pouco importa que essas formas devam figurar explicitamente no discurso ou possam aí permanecer implícitas" (BENVENISTE, 1988, p. 279).

Nesse sentido, os famosos estudos de Benveniste acerca do sistema pronominal francês, por exemplo, estudos nos quais ele formula a clássica distinção entre pessoa e não pessoa ("eu" e "tu", de um lado, e "ele", de outro) 6 , não podem ser tomados como meras descrições de língua (no caso, da língua francesa). Eles ancoram na descrição linguística fina algo que é de natureza mais geral, universal, que pode ser definido como uma posição do homem na linguagem - que se mostra nas línguas -, necessária ao uso que se faz das línguas, logo, ao discurso.

Não seria absurdo dizer que, levado em conta o pensamento de Émile Benveniste, as categorias de pessoa, tempo e espaço são universais antropológicos que constituem a linguagem e que se mostram nas línguas. Que argumentos podem ser encontrados em Benveniste que autorizam essa conclusão?

Considere-se, a título de exemplo, apenas a categoria de pessoa. As demais categorias exigiriam também análise detida, mas, acredita-se, muito do que pode ser dito acerca da pessoa pode ser estendido às outras categorias.

Inicialmente, o motivo que conduz a interpretação aqui defendida decorre do uso feito por Benveniste das expressões "o homem na linguagem" e "o homem na língua"7 - a primeira, no "Prefácio" de Problemas de linguística geral l; a segunda, no sumário de Problemas de linguística geral I e II, intitulando a quinta parte dos livros. O linguista diz colocar sob esses títulos "[...] a marca do homem na linguagem, definida pelas formas linguísticas da 'subjetividade' e as categorias de pessoa, dos pronomes e do tempo" (BENVENISTE, 1988, s. p., destaque do autor). Essas expressões, na verdade, sintetizam um posicionamento teórico que foi levado a cabo por Benveniste em todas as investigações que operou, incluídas aí as análises enunciativas, certamente, mas também as análises comparativistas e as de linguística geral.

Para ele, o homem está presente na linguagem, é dela constitutivo (e vice-versa); da mesma forma, e por essa mesma razão, ele está presente na língua (e nas línguas), através de categorias como a de pessoa, a de tempo e a de espaço. Ora, essas categorias são as formas linguísticas da subjetividade, esta, por sua vez, entendida não como uma essência emocional, cognitiva ou psíquica, mas como uma propriedade da linguagem que se apresenta nas línguas quando o homem fala. É o próprio Benveniste quem explica:

A "subjetividade" de que tratamos aqui é a capacidade do locutor para se propor como "sujeito". Define-se não pelo sentimento que cada um experimenta de ser ele mesmo (esse sentimento, na medida em que podemos considerá-lo, não é mais que um reflexo) mas como a unidade psíquica que transcende a totalidade das

\footnotetext{
${ }^{6}$ Por exemplo, os artigos: "Estrutura das relações de pessoa no verbo", "As relações de tempo no verbo francês", "A natureza dos pronomes" e o próprio "Da subjetividade na linguagem", presentes em Problemas de linguística geral I (cf. Referências).

${ }^{7}$ Sobre essa oscilação de uso das expressões, ver Flores (2013b).
} 
experiências vividas que reúne, e que assegura a permanência da consciência. Ora, essa "subjetividade", quer a apresentemos em fenomenologia ou em psicologia, como quisermos, não é mais que a emergência no ser de uma propriedade fundamental da linguagem. É "ego" quem diz ego. Encontramos aí o fundamento da "subjetividade" que se determina pelo status linguístico de "pessoa" (BENVENISTE, 2006, p. 259-260, destaques do autor).

Essa passagem já foi tantas vezes repetidas em inúmeros textos - de linguística ou não - que se corre o risco de não mais ler o que há de tão especial nela. Benveniste assegura aí três aspectos essenciais de sua proposta: em primeiro lugar, a subjetividade é uma capacidade que cada homem, cada locutor, tem de se apresentar como sujeito, como único; em segundo lugar, a subjetividade é uma propriedade da línguagem; em terceiro lugar, a subjetividade tem status linguístico, a categoria de pessoa.

Bem entendido, isso significa que a subjetividade não é uma essência, e a noção de "pessoa", cujo status é linguístico, é o seu fundamento linguístico. Aliás, Benveniste (1988, p. 287) pergunta textualmente: "terá de ser linguístico esse fundamento? Onde estão os títulos da linguagem para fundar a subjetividade?". E responde: “de fato, a linguagem corresponde a isso em todas as suas partes. É tão profundamente marcada pela expressão da subjetividade que nós nos perguntamos se, construída de outro modo, poderia ainda funcionar e chamar-se linguagem" (BENVENISTE, 1988, p. 287). Mais adiante, determina: "uma língua sem a expressão de pessoa é inconcebível" (BENVENISTE, 1988, p. 287).

Assim, "o homem na linguagem" se mostra como "homem na língua" através de análises linguísticas que revelam a capacidade que cada um tem de ser sujeito. Nesse sentido, fazer-se presente na língua - uma vez que está na linguagem - é uma função essencial desse homem, o que torna essa presença objeto de uma antropologia da linguagem, porque é da natureza do homem que venha a se singularizar como falante de sua língua.

A categoria de pessoa - e isso deveria ser mais bem investigado ainda ${ }^{8}$ - parece ser um assunto que integra estudos linguísticos, históricos, antropológicos, psicanalíticos, sociais etc. ${ }^{9}$ Do ponto de vista linguístico, tudo indica que seu estudo pode redimensionar os termos pelos quais o falante pode ser contemplado em uma teoria da linguagem.

O tempo é outra categoria de linguagem que, ao se mostrar nas línguas, dá a ver a "presença" do homem na linguagem e na língua: "das formas linguísticas reveladoras da experiência subjetiva, nenhuma é tão rica quanto aquelas que exprimem o tempo" (BENVENISTE, 1989, p. 70, destaque do autor). Mas de qual tempo Benveniste está tratando? É bom precisar isso. Cabe, portanto, começar com uma advertência do autor:

Uma confusão muito difundida é a de crer que certas línguas ignoram o tempo, pelo fato de que, não fazendo parte da família das línguas flexionais, elas parecem não ter verbo. Subtende-se que somente o verbo permite exprimir o tempo. Há nisto muita confusão que se deve denunciar: a categoria do verbo pode ser reconhecida mesmo nas línguas não flexionais, e a expressão do tempo é

\footnotetext{
${ }^{8}$ Ver, por exemplo, o número 3 da revista Faits de langues, inteiramente dedicado a essa categoria.

${ }^{9}$ Ver, por exemplo, Gyekye (2002) e Adeofe (2004).
} 
compatível com todos os tipos de estruturas linguísticas. A organização paradigmática própria às formas temporais de certas línguas, notadamente das línguas indo-europeias, não tem o direito nem o privilégio exclusivo de exprimir o tempo (BENVENISTE, 1989, p. 70).

A passagem é clara: para Benveniste, nenhuma língua pode ignorar o tempo. E mais: não é apenas o verbo que pode expressar tempo. Ora, o tempo do qual fala o autor não é aquele que se costuma ensinar em aulas de gramática (tanto de língua materna como de língua estrangeira). O tempo aqui estudado é o tempo da enunciação, também chamado de tempo da fala, um tempo que tem como característica singular "[...] o fato de estar organicamente ligado ao exercício da fala, o fato de se definir e de se organizar como função do discurso" (BENVENISTE, 1989, p. 74). Ou seja, esse tempo “[...] tem seu centro - um centro ao mesmo tempo gerador e axial - no presente da instância da fala" (BENVENISTE, 1989, p. 74). Nesse sentido, "cada vez que um locutor emprega a forma gramatical do 'presente' (ou uma forma equivalente), ele situa o acontecimento como contemporâneo da instância do discurso que o menciona" (BENVENISTE, 1989, p. 74-75, destaque do autor).

Bem entendido, o tempo da fala não coincide nem com o presente formal, nem com qualquer outro tempo que os compêndios gramaticais elencam para as línguas. Na verdade, ocorre o contrário: o locutor situa os acontecimentos "presentes", "passados" ou "futuros", constitutivos da estrutura léxico-gramatical das línguas, em relação ao fato de ele falar. Em suma, o presente da fala é o fundamento das oposições temporais da língua e

[...] constitui a linha de separação entre dois outros momentos engendrados por ele e que são igualmente inerentes ao exercício da fala: o momento em que o acontecimento não é mais contemporâneo do discurso, deixa de ser presente e deve ser evocado pela memória, e o momento em que o acontecimento não é ainda presente, virá a sê-lo e se manifesta em prospecção (BENVENISTE, 1989, p. 75).

Nessa perspectiva, existe apenas uma realidade temporal, a do presente, que é, por natureza, implícito a cada fala de cada homem: "quando ele é explicitado formalmente, é por uma dessas redundâncias frequentes no uso quotidiano" (BENVENISTE, 1989, p. 75). Os tempos que não são presentes (passado e futuro), porém, são explicitados na língua, porque ela os situa "como pontos vistos para trás ou para frente a partir do presente" (BENVENISTE, 1989, p. 75, destaque do autor). Ou seja, "a língua deve, por necessidade, ordenar o tempo a partir de um eixo, e este é sempre e somente a instância de discurso" (BENVENISTE, 1989, p. 75).

As consequências disso são muitas: em primeiro lugar, existe apenas um tempo inerente à língua - e isso, em qualquer língua -, que é o tempo da fala do locutor. Tudo o que é dito se organiza em relação ao fato de a fala do locutor ter lugar em uma dada instância. Em segundo lugar, as demais referências temporais estão situadas entre o que não é mais o presente e o que ainda virá a ser, são "[...] visões sobre o tempo, projetadas para trás e para frente a partir do ponto presente" (BENVENISTE, 1989, p. 76). E, como diz Benveniste, "esta parece ser a experiência fundamental do tempo, de que todas as línguas dão testemunho à sua maneira" (BENVENISTE, 1989, p. 76). 
Reencontra-se, aqui, em relação ao tempo, tal como em relação à pessoa, a ideia de que as línguas testemunham pela linguagem.

Cabe observar, aqui, que o tempo da fala é apresentado por Benveniste como mais uma categoria da linguagem - universal, portanto - que se mostra nas línguas. Porém, assim como a categoria de pessoa, também o tempo é individual, na medida em que ele é relativo àquele que fala. Há uma individualidade que é constitutiva da generalidade da categoria na linguagem e da sua particularidade nas línguas. Isso, entretanto, não implica uma individualidade solipsista, pois o ato de fala, a enunciação, é sempre intersubjetivo, na medida em que revela que o "eu" e o outro estão implicados.

Quanto ao espaço, Benveniste é normalmente mais resumido em seu tratamento, mas encontra-se em sua obra alguma consideração sobre, como por exemplo:

indicando os objetos, os demonstrativos organizam o espaço a partir de um ponto central, que é Ego, segundo categorias variáveis: o objeto está perto ou longe de mim ou de ti, ele é também orientado (defronte ou detrás de mim, no alto ou em baixo), visível ou invisível, conhecido ou desconhecido, etc. O sistema das coordenadas espaciais se presta também para localizar todo objeto em qualquer campo que seja, uma vez que aquele que o organiza está ele-próprio designado como centro e ponto de referência (BENVENISTE, 1989, p. 69-70).

Quer dizer, a categoria de espaço pode ser entendida como sistema de coordenadas espaciais, organizado a partir de um ponto central que é "eu", e segundo modalidades variáveis. A categoria de espaço se presta também para localizar todo objeto em qualquer campo que seja, uma vez que aquele que o organiza está, ele próprio, designado como centro e ponto de referência.

\section{Palavras finais}

Para concluir, é importante evocar uma ideia de Benveniste que foi acima apenas tangencialmente lembrada: a enunciação, noção explicitamente formulada em 1970, em artigo quase homônimo, "O aparelho formal da enunciação".

O texto é, na verdade um ponto de chegada das reflexões do linguista, elaboradas em uma longa vida de estudos, o que significa que a noção de enunciação, embora textualmente formulada apenas em 1970, é algo com o qual Benveniste já opera desde muito cedo em sua teoria da linguagem ${ }^{10}$. Nesse texto, lê-se: "a enunciação é este colocar em funcionamento a língua por um ato individual de utilização" (BENVENISTE, 1989, p. 82).

Essa ideia - cuja aparente clareza decorre da estrutura definitória - tem um alcance ainda não totalmente dimensionado nos estudos da linguagem. Com ela, Benveniste inaugura o que Agamben (2006), muito apropriadamente, chamou de o "ter lugar na linguagem" (AGAMBEN, 2006, p. 105), ou ainda: "a esfera da enunciação compreende [...] aquilo que, em todo o ato de fala, se refere exclusivamente ao seu ter-lugar, à sua instância, independentemente e antes daquilo que, nele, é dito e significado" (AGAMBEN, 2006, p. 43,

\footnotetext{
${ }^{10}$ Sobre a gênese da noção de enunciação, ver Ono (2007).
} 
destaque do autor).

Esse "ter-lugar" advém nas línguas pelas categorias de pessoa e de tempo aqui estudadas $^{11}$. Trata-se de uma dimensão em que a experiência do tornar-se falante é reeditada. A cada vez que alguém fala, reitera-se a experiência - da qual não há lembrança possível para o homem - de um dia passar a falar uma língua. A cada vez que o homem enuncia, reatualiza-se a experiência do tornar-se falante de uma língua (universal-particularsingular). Isso deveria interessar mais aos linguistas.

\section{Referências}

ADEOFE, Leke. Personal Identity in African Metaphysics. In: BROWN, Lee (ed.) African Philosophy: New and Traditional Perspectives. New York: Oxford UP, 2004. p. 69-86. https://doi.org/10.1093/019511440X.003.0005

AGAMBEN, Giorgio. A linguagem e a morte - Um seminário sobre a negatividade. Tradução de Henrique Burigo. Belo Horizonte: Editora UFMG, 2006.

BENVENISTE, Émile. Problemas de linguística geral I. Tradução de Maria da Glória Novak e Maria Luisa Neri. Campinas: Editora da UNICAMP, 1988.

BENVENISTE, Émile. Problemas de linguística geral II. Tradução de Eduardo Guimarães et al. Campinas: Editora da UNICAMP, 1989.

BENVENISTE, Émile. Problèmes de linguistique générale, II. Paris: Éditions Gallimard, 2005.

BENVENISTE, Émile. Problèmes de linguistique générale, I. Paris: Éditions Gallimard, 2006.

FLORES, Valdir do Nascimento. Introdução à teoria enunciativa de Benveniste. São Paulo: Parábola, 2013a.

FLORES, Valdir do Nascimento. Sujeito da enunciação: singularidade que advém da sintaxe da enunciação. DELTA, São Paulo, v. 29, n. 1, p. 95-120, 2013b. https://doi.org/10.1590/S0102-44502013000100005

FLORES, Valdir do Nascimento. Problemas gerais de linguística. Petrópolis: Vozes, 2019.

CULIOLI, Antoine. Pour une linguistique de l'énonciation. Paris: OPHRYS, 1999.

FAITS DE LANGUES. Paris: Ophrys, n. 3, mar. 1994. Disponível em: www.persee.fr/issue/flang_1244-5460_1994_num_2_3. Acesso em: 15 set. 2019. https://doi.org/10.3406/flang.1994.901

GYEKYE, Kwame. Person and Community in African thought. In: COETZEE, Peter H.; ROUX, Abraham P. J. (Eds.). The African Philosophy Reader. New York: Routledge, 2002. p. 297-312.

ONO, Aya. La notion d'énonciation chez Émile Benveniste. Limoges: Lambert-Lucas, 2007.

Recebido em: 09/12/2019.

Aceito em: 09/03/2019.

\footnotetext{
${ }^{11}$ Há outras que poderiam também ser incluídas nesse rol, como, por exemplo, a categoria de espaço. Também esta integra o campo da enunciação. O lugar da categoria de espaço no conjunto das categorias que integram a enunciação e dos aspectos de universalidade/particularidade que evoca é tema de estudo em Flores (2019).
} 